\title{
Investigating the sexual protective behaviour among HIV-positive women in Tehran, Iran
}

\author{
Zeinab Talebi ${ }^{1}$, Razieh Lotfi², Kourosh Kabir ${ }^{2,3}$, Farahnaz Meschi' ${ }^{4}$ Zahra Bayat Jozani' ${ }^{5}$, Minoo Mohraz \\ ${ }^{1}$ Student Research Committee, Alborz University of Medical Sciences, Karaj, Iran \\ ${ }^{2}$ Social Determinants of Health Research Center, Alborz University of Medical Sciences, Karaj, Iran \\ ${ }^{3}$ Department of Community Medicine, School of Medicine, Alborz University of Medical Sciences, Karaj, Iran \\ ${ }^{4}$ Islamic Azad University, Karaj Branch, Karaj, Iran \\ ${ }^{5}$ Iranian Research Center for HIV/AIDS, Iranian Institute for Reduction of High-Risk Behaviors, Tehran University of Medical Sciences, \\ Tehran, Iran
}

\begin{abstract}
Introduction: The third wave of human immunodeficiency virus (HIV) is rising due to high-risk sexual behaviours in Iran. In spite of launching programs to combat HIV in Iran, condom use frequency has not yet reached the optimal level, especially in high-risk groups. The aim of this study was to assess the sexual protection behaviours and awareness among HIV-positive women.

Material and methods: This descriptive study was performed on $100 \mathrm{HIV}$-positive women who referred to the Voluntary and Counselling Centre (VCT) in Tehran and were recruited using a purposive sampling method. Data collection was carried out using HIV/acquired immunodeficiency syndrome (AIDS) awareness and sexual protection behaviour questionnaires.

Results: Condom use was practiced only by $22.2 \%$ in all their vaginal and anal sexual intercourse during the three months, and $77.8 \%$ of the women never used condoms or failed to use them continuously. Their sexual partners were HIV-positive in $71 \%$ of cases. The mean \pm SD of awareness score about HIV/AIDS was $7.60 \pm 3.31$, indicating average awareness of the subjects in the study. A total of $49.1 \%$ of the participants stated that their sexual partners' reluctance was the most important reason for non-use of condoms, while women were not willing to use condoms in $18.2 \%$ of cases.

Conclusions: The results of the present study indicated poor sexual protection behaviours in HIV-positive women. As a result, gender-based harm reduction programs to promote safe sexual behaviour, awareness level, and negotiation power for condom use in HIV-positive women is more important than ever.
\end{abstract}

HIV AIDS Rev 2019; 18, 3: 215-221

DOI: https://doi.org/10.5114/hivar.2019.88269

Key words: protective sexual behaviour, HIV, condoms, HIV awareness.

\section{Introduction}

The risk of human immunodeficiency virus (HIV) transmission has increased in recent years due to high-risk sexual behaviours, considering the available statistics and the demo- graphic structure of Iran [1]. According to a World Health Organisation (WHO) report, global HIV infections reached 36.9 million in 2017, of which 18.2 million were women over the age of 15. The number of Iranian HIV-positive individuals is estimated at around 60,000 people, of whom approximately

Article history:

Received: 14.03.2019

Received in revised form: 20.04.2019

Accepted: 07.05.2019

Available online: 09.09.2019
International Journal

of HIV-Related Problem

HIV \& AIDS

R e v i e w 
15,000 are women [2]. The number of Iranian HIV-positive women grew from about $7 \%$ in 2015 to $11 \%$ in 2016 and about $17 \%$ in 2017 [3]. However, according to the announcement of Iran's comprehensive electronic data management system for HIV, $31 \%$ and $69 \%$ new recorded cases were women and men, respectively, in the first half of 2018.

In addition to changes in the incidence of males and females, the transmission routes have undergone changes in recent years. The causes of HIV among all the cases recorded since 1986 up to now in the country include injection with shared needles among drug users (67.5\%), sexual intercourse (18.7\%), mother-to-child transmission (MTCT) (1.6\%), and unknown causes (11.5\%). However, among the cases detected in the first six months of 2018 , the transmission routes included drug injecting (37\%), MTCT (2\%), unclear causes (21\%), and sexual intercourse (40\%) [4]. The share of sexual transmission route was about $5-8 \%$ in 2006 , but it increased to $13 \%$ by 2008 . This figure reached $21.1 \%$ of the total population in 2011, and the injection transmission route grew in the spread of HIV/acquired immunodeficiency syndrome (AIDS) more than six fold. The share of sexual transmission was stated as $47.1 \%$ in the first six months of 2017 . In addition, the transmission route was unclear in $17.4 \%$ of the cases, so it could be conjectured that sexual transmission accounted for the majority of cases [5].

Because women make up a large number of patients identified in the third wave of the HIV epidemic in Iran, during the process of moving the HIV transmission route to the third wave, spouses, sexual partners, and mothers of the second wave play the key role. These women are actively or passively affected by the disease due to high-risk and unprotected sexual behaviours, and their role in the HIV/ AIDS epidemic is of increasing importance due to the transmission of the virus during pregnancy or birth to subsequent generations [6].

Many HIV-positive women are deprived of desirable sexual and fertility health due to gender inequalities, which are part of their rights. Gender inequality, access to low economic resources, unbalanced power in relationships, and limited ability to decide about sex limit the ability of many HIV-positive women to meet their sexual and fertility health needs [7]. Understanding how gender affects the risk of HIV infection and that it accounts for higher HIV transmission cases than drug injection is key to designing effective prevention and treatment programs [8]. HIV prevention programs often consider men and women equally responsible for making sexual decisions and using condoms, but it should be noted that they ignore the fact that gender-based power in relationships between women and their sexual partners/spouses affect sexual behaviours because society defines different norms for women and men $[9,10]$. For example, some societies have considered the right for men to have multiple sexual partners [11], and men, for the sake of their masculinity, sometimes choose multiple sexual partners extra-martially, which in turn reduces emotional intimacy with their wives, and even the frequency of condom use. However, women are expected play a gender role paral- lel to the duty of femininity to serve the family, respect their husbands, be obedient, and to remain sexually loyal [12].

Given that there is still no definitive treatment for AIDS, and prevention is the only way to combat this disease, and since this disease is often acquired through avoidable and modifiable behaviours, the most important barrier to AIDS prevention is the lack of awareness of different aspects of the disease, and educating and informing people, especially women, can be considered as an appropriate strategy to prevent new cases [13]. Safe sex practices became important in the late 1980s as a result of the AIDS epidemic and are now considered as one of the sexual education goals and harm reduction strategies to reduce related risks [18]. Safe sexual activity refers to sexual activities, particularly sexual penetration, and it is carried out using latex condoms and monogamy, with the aim of reducing sexually transmitted diseases such as HIV [19]. In this regard, condom use has always been the most effective preventive and cost-effective way to deal with sexually transmitted diseases [14].

Safe sexual behaviour in different groups is related with appropriate education and knowledge about sexually transmitted diseases and HIV/AIDS, strong self-efficacy, access to condoms, access to healthcare services, strong support from health personnel, and discourse skills regarding the use of condoms and promotion of safe sex is an effective method to control the transmission of HIV and other infections [15]. Therefore, the present study was aimed to measure the frequency of sexual-protection behaviours among HIV-positive women and their awareness of HIV/AIDS and its transmission and prevention routes, so that its results can be used to evaluate preventive programs and design interventions to improve decisions made around sexuality and reproduction.

\section{Material and methods}

This descriptive-analytical study was performed on 100 HIV-positive women referring to a VCT in Tehran, which is one of the largest referral VCTs in Tehran University of Medical Sciences. Approximately 3000 people are covered by this centre, which mainly focuses on AIDS and sexually transmitted diseases. The medical and psychological services are provided free of charge and on a daily basis in the centre. Education, free and confidential HIV counselling, and testing services to reduce the harm caused by addiction (distribution of syringes and needles), and the provision of condoms are among the services provided at these centres. Convenience sampling was carried out after expressing the goals of the study to the participants and obtaining their informed consent during a 45-day period. Inclusion criteria were as follows: 1) Iranian nationality; 2) individuals aged 19 to 49 years; 3 ) the ability to read and write; and 4) being sexually active during the preceding three months. Exclusion criteria also included: 1) progression to advanced stages of the disease (AIDS); 2) unwillingness to participate in the study; 3) severe mental diseases; 4) intent to be pregnant; and 5) being absent from training classes during the preceding six months. Of the 138 people referred, 100 met the in- 
clusion criteria. Each participant received a specific code so that the researcher could identify those who did not want to reveal their name.

\section{Measurement tools}

Data was collected by a 57 -item questionnaire. The questionnaire consisted of three parts and was drawn up by a questionnaire designed and underwent psychometric analysis by Lotfi et al. The first part contained demographic profiles (22 questions). The next part included the fertility and sexual behaviour profiles of people, and the scoring was done using a five-point Likert scale ranging from always to never. Individuals were categorised as having safe sexual behaviour if they chose the always option regarding condom use during anal and vaginal intercourse. Thus, Score 10 represents safe sexual behaviour. Then a 12-item HIV awareness questionnaire was used, and scores 1 and 0 were assigned to correct or wrong/do not know answers, respectively. Scores 0-4, 5-8, and 9-12 indicated poor, moderate, and good level of awareness, respectively. The reliability of the questionnaire was confirmed by a test-retest method with a correlation coefficient of 0.88 and Cronbach's alpha of 0.78 [16].

\section{Data analysis}

Data description was carried out using mean, number, and percentage in SPSS ver. 16 software. Finally, the level of awareness and safe sexual behaviour (continuous use of condoms in all types of sexual intercourse in the last three months) were examined.

\section{Ethical considerations}

This study was done after being approved by the Ethics Committee of the Alborz University of Medical Sciences with code IR.ABZUMS.REC.1397.31.

\section{Results}

In total $69 \%$ of the participants had permanent marriage for one time. Moreover, they were categorised in the second decile in terms of their income level. A total of $89 \%$ of these individuals mentioned that they possessed no other financial resources, such as savings, property, and valuable objects, and $69 \%$ of them stated that they had sometimes borrowed money from others to earn a living. Participants stated that they had sex once a week (37\%), two/three times a week (48\%), and more than four times a week (15\%). Other demographic and fertility information can be seen in Table 1. Also, a total of $53.5 \%$ of the participants stated that they were currently having sex with their favourite sexual partner; however, only $37.7 \%$ of them always used condoms and $20.7 \%$ of them never used condoms during their sexual intercourse. Table 2 shows the frequency of using condoms and safe sexual behaviour. A total of $30 \%$ of women suffered from abnormal secretions, wounds, and warts. $95.8 \%$ and $80.4 \%$ of the individuals never used drugs and alcohol before sex, respectively. Mean and standard deviation of awareness score in participants was $7.60 \pm 3.31$. Table 3 shows the participants' level of awareness of the questionnaire items. Examining the inter-variable correlation showed that the average frequency of safe sexual behaviour was $43.27 \%$ in those whose spouse was HIV-positive, which is less than those who had healthy husbands (67.07\%). The results also showed a significant relationship between the average frequency of safe sexual behaviour with the spouse's level of education ( $p=0.029)$; meaning that the average frequency of safe sexual behaviour was higher (65.34\%) in individuals whose spouses had an academic education and $41.90 \%$ in those with middle school and high school education. In addition, it was observed that the average frequency of safe sexual behaviour in housewives $(55.77 \%$ ) was higher than among employed women (42.40\%).

In this study, $62 \%$ of people did not have the correct information about oral sex-induced HIV. A total of $36 \%$ of respondents chose the correct answer in replying to the phrase: "If the man's sperm is not poured in to the woman's reproductive system during the intercourse, HIV/AIDS infection doesn't occur", and $49 \%$ of people thought that if a man has undergone vasectomy, he will no longer be a carrier of HIV through sex. Participants had moderate awareness levels of HIV transmission through anal sex (59.6\%), and positive diagnostic test for HIV (57\%), and had relatively good awareness level in other cases. In addition, $90 \%$ of the participants noticed that the normal appearance of individuals would not be a sign of lack of infection, which indicates a good level of awareness regarding this subject.

Also, there was a significant positive correlation between the awareness level and the duration of the disease $(p=0.001)$ and duration of membership in the club $(p=0.005)$. However, there was no significant relationship between awareness level and safe sexual behaviour $(p=0.97)$. There was no correlation between the sexual behaviour and awareness level with other variables.

\section{Discussion}

The aim of this study was to investigate the protection sexual behaviour and people's level of awareness of HIV, its transmission routes, and prevention strategies in HIV-positive women. The results reveal that only $22.2 \%$ of HIV-positive people in this study had safe sex behaviours and used condoms in all of their vaginal and anal sexual intercourse; other people never used condoms or only sometimes used them in their sexual intercourse. Consistent condom use reduces the probability of HIV transmission per sex act by as much as $95 \%$ and reduces the annual HIV incidence in sero-discordant couples by $90-95 \%$ when used consistently [17]. However, risky sexual behaviour among HIV-positive people was reported in many studies, and consistent condom use varies from $16.7 \%$ [18] to $43 \%$ [19]. In another 
Table 1. Demographic characteristics and fertility of the participants

\begin{tabular}{|c|c|}
\hline Variables & Mean \pm SD \\
\hline Age (years) & $43.35 \pm 7.03$ \\
\hline Age at first sex & $19.57 \pm 4.2$ \\
\hline Duration of the disease & $5.52 \pm 4.36$ \\
\hline Duration of membership in a Positive club & $3.23 \pm 2.91$ \\
\hline \multirow[t]{2}{*}{ Average monthly income (IRR) } & $\begin{array}{c}1,381,521 \pm \\
1,532,625.36\end{array}$ \\
\hline & $n(\%)$ \\
\hline \multicolumn{2}{|l|}{ Marital status } \\
\hline Married (permanent marriage) & $51(51)$ \\
\hline Married (temporary marriage) & $17(17)$ \\
\hline Single & $6(6)$ \\
\hline Widow & $6(6)$ \\
\hline Divorced & $20(20)$ \\
\hline \multicolumn{2}{|l|}{ Residential status } \\
\hline Independent home & $31(31)$ \\
\hline Rental house & $64(64)$ \\
\hline Centre for dormitory & $2(2)$ \\
\hline Without shelter & $3(3)$ \\
\hline \multicolumn{2}{|l|}{ Number of partners } \\
\hline 1 & $50(50)$ \\
\hline $2-3$ & $35(35)$ \\
\hline $4-5$ & $8(8)$ \\
\hline 6 or more & $7(7)$ \\
\hline Having a contraception method & $79(79)$ \\
\hline \multicolumn{2}{|l|}{ Type of contraception method } \\
\hline Withdrawal & $27(32.9)$ \\
\hline Condom & $46(56.1)$ \\
\hline Intra Uterine Device & $4(4.9)$ \\
\hline Tubal ligation & $5(6.1)$ \\
\hline \multicolumn{2}{|l|}{ Level of education } \\
\hline Elementary and middle school & $25(25)$ \\
\hline High school and diploma & $60(60)$ \\
\hline Academic & $15(15)$ \\
\hline Spouse's condition $\left(\mathrm{HIV}^{+}\right)$ & $71(71)$ \\
\hline \multicolumn{2}{|l|}{ Spouse education level } \\
\hline Illiterate & $8(8.2)$ \\
\hline Elementary and middle school & $37(37.8)$ \\
\hline High school and diploma & $34(34.7)$ \\
\hline Academic & $19(19.3)$ \\
\hline \multicolumn{2}{|l|}{ Wife's addiction status } \\
\hline Injection drug addiction & $17(17.3)$ \\
\hline Non-injectable addiction & $27(27)$ \\
\hline
\end{tabular}

Table 1. Cont.

\begin{tabular}{|c|c|}
\hline & $n(\%)$ \\
\hline \multicolumn{2}{|l|}{ Employment status } \\
\hline Unemployed & $59(59)$ \\
\hline Employed & $41(41)$ \\
\hline \multicolumn{2}{|l|}{ Husband's employment status } \\
\hline Unemployed & $28(28 / 6)$ \\
\hline Employed & $70(71 / 4)$ \\
\hline \multicolumn{2}{|l|}{ Route of HIV contamination } \\
\hline Unsafe sex & $65(65)$ \\
\hline Injecting drug use & $4(4)$ \\
\hline Blood injection & $3(3)$ \\
\hline Unknown & $19(19)$ \\
\hline Other cases & $9(9)$ \\
\hline \multicolumn{2}{|l|}{ Reasons not to use condom } \\
\hline No condom & $5(9.1)$ \\
\hline Expensive & $2(3.6)$ \\
\hline Missing woman's interest in using & $10(18.2)$ \\
\hline Opposition by husband/sex partner & $27(49.1)$ \\
\hline Use of other preventive methods & $5(9.1)$ \\
\hline Inattentiveness of condom use & $3(5.5)$ \\
\hline Negative husband/partner test & $1(1.8)$ \\
\hline Confidence in husband/partner & $2(3.6)$ \\
\hline Use of antiretroviral drugs & $94(94)$ \\
\hline
\end{tabular}

study from Iran, only $25 \%$ of people living with HIV always used condoms in the preceding year [20].

Even in high-risk groups such as female sex workers (FSWs) not using condom is very common, and almost all FSWs had not used condoms regularly [21].

The most important reason for non-use of condoms in this study was the sexual partner's opposition (49.1\%). Other reasons were reported as follows: the woman's unwillingness (18.2\%), lack of access to condoms (9.1\%), and the use of other preventive methods (9.1\%). Although men and women may have similar reasons for non-use of condoms, it should be pointed out that men have more control over the use or non-use of condoms [10,22], and these are men who play a key role in gender equality, because males play a fundamental role in almost every area of life, ranging from personal decisions about the number of children in the family to decisions about government policy or programs at all levels in most societies [23]. In studies conducted on highrisk women in Iran, results showed that the most important reason for non-use of condoms was reported to be the sexual partner's opposition [20, 24]. Therefore, a change in awareness, attitude, and the behaviour of men and women is necessary to coordinate participation in both genders [8], and there must be approaches to gender inequality so that 
Table 2. Sexual behaviour and condom use in sexual relationships

\begin{tabular}{|c|c|}
\hline Variables & $n(\%)$ \\
\hline \multicolumn{2}{|c|}{$\begin{array}{l}\text { The average amount of condom use per } 10 \text { vaginal sexual } \\
\text { intercourses }\end{array}$} \\
\hline Never & $35(35)$ \\
\hline $1-5$ times & $28(28)$ \\
\hline $9-5$ times & $10(10)$ \\
\hline Always & $27(27)$ \\
\hline \multicolumn{2}{|c|}{ The use of condom in last vaginal sex } \\
\hline Yes & $42(42)$ \\
\hline No & $56(56)$ \\
\hline I don't know & $2(2)$ \\
\hline Anal sex & $21(21)$ \\
\hline \multicolumn{2}{|c|}{ Condom use in last anal sex } \\
\hline Yes & $13(65)$ \\
\hline No & $6(30)$ \\
\hline I don't know & $1(5)$ \\
\hline
\end{tabular}

Table 2. Cont.

\begin{tabular}{l|c}
\hline Variables & $n(\%)$ \\
\hline Oral sex & $39(39)$ \\
\hline \begin{tabular}{l} 
Condom use in last oral sex \\
\hline Yes
\end{tabular} & $3(7.3)$ \\
\hline No & $34(82.9)$ \\
\hline I don't know & $4(9.8)$ \\
\hline Condom use in oral sex within three months
\end{tabular}

Condom use in oral sex within three months

\begin{tabular}{l|c}
\hline Always & $4(10.8)$ \\
\hline Most of the time & $1(2.7)$ \\
\hline Sometimes & $3(8.1)$ \\
\hline Seldom & $7(18.9)$ \\
\hline Never & $22(59.5)$ \\
\hline
\end{tabular}

Type of sexual behaviour

\begin{tabular}{l|l}
\hline Safe sex & $22(22.2)$ \\
\hline Unsafe sex & $77(77.8)$ \\
\hline
\end{tabular}

Table 3. The results of the participants' response

\begin{tabular}{|c|c|c|c|c|}
\hline \multirow[t]{2}{*}{ Questions } & \multirow[t]{2}{*}{ Answers } & \multicolumn{3}{|c|}{ Result } \\
\hline & & (\%) & $n$ & Mean \\
\hline \multirow{2}{*}{ If treated, HIV/AIDS infection can be completely removed from the body. } & True & 65 & 65 & \multirow{2}{*}{0.65} \\
\hline & False/I don't know & 35 & 35 & \\
\hline \multirow{2}{*}{ HIV/AIDS infection can also be transmitted through oral sex. } & True & 38 & 38 & \multirow{2}{*}{0.38} \\
\hline & False/I don't know & 62 & 62 & \\
\hline \multirow{2}{*}{$\begin{array}{l}\text { The risk of HIV/AIDS transmission can be reduced by using condoms in sexual } \\
\text { intercourse. }\end{array}$} & True & 87 & 87 & \multirow{2}{*}{0.87} \\
\hline & False/I don't know & 13 & 13 & \\
\hline \multirow{2}{*}{$\begin{array}{l}\text { HIV/AIDS transmission doesn't occur if the sperm does not enter the female } \\
\text { reproductive system during sexual intercourse. }\end{array}$} & True & 36.4 & 36 & \multirow{2}{*}{0.36} \\
\hline & False/I don't know & 63.6 & 63 & \\
\hline \multirow{2}{*}{ Anal sex is associated with a greater risk of HIV/AIDS transmission. } & True & 59.6 & 59 & \multirow{2}{*}{0.59} \\
\hline & False/I don't know & 40.4 & 40 & \\
\hline \multirow{2}{*}{$\begin{array}{l}\text { The use of a shared bathroom and bathtub does not lead to the transmission } \\
\text { of HIV/AIDS. }\end{array}$} & True & 68 & 68 & \multirow{2}{*}{0.68} \\
\hline & False/I don't know & 32 & 32 & \\
\hline \multirow{2}{*}{ Having sex with strangers increases the risk of HIV/AIDS infection. } & True & 82 & 82 & \multirow{2}{*}{0.82} \\
\hline & False/I don't know & 18 & 18 & \\
\hline \multirow{2}{*}{ HIV / AIDS diagnostic test can show HIV/AIDS infection immediately after sex. } & True & 57 & 57 & \multirow{2}{*}{0.57} \\
\hline & False/I don't know & 43 & 43 & \\
\hline \multirow{2}{*}{ Limiting sex with only one person can reduce the risk of HIV/AIDS infection. } & True & 71 & 71 & \multirow{2}{*}{0.71} \\
\hline & False/I don't know & 29 & 29 & \\
\hline \multirow{2}{*}{ A man whose tubes are closed does not transmit HIV/AIDS to his wife. } & True & 49 & 49 & \multirow{2}{*}{0.49} \\
\hline & False/I don't know & 51 & 51 & \\
\hline \multirow{2}{*}{ A woman whose tubes are closed is no longer infected with HIV/AIDS. } & True & 61 & 61 & \multirow{2}{*}{0.61} \\
\hline & False/I don't know & 39 & 39 & \\
\hline \multirow{2}{*}{ A person with a healthy appearance may be infected with HIV/AIDS. } & True & 90 & 90 & \multirow{2}{*}{0.90} \\
\hline & False/I don't know & 10 & 10 & \\
\hline
\end{tabular}


HIV-positive women are empowered, thereby improving sexual and reproductive health and its consequences [7].

The participants had a moderate awareness about HIV prevention. Studies revealed that consistent condom use is associated with participation in an HIV prevention course, knowledge of unsafe sex consequences, and having an HIV-positive sexual partner [18]. However, many highrisk groups do not have adequate awareness of the modes of transmission of HIV, doubt about the role of condoms in preventing HIV, and face reluctance of sexual partners to use condoms due to reduced sexual pleasure [21]. Considering the importance of knowledge about HIV/AIDS in reducing risky sexual behaviour [13], more informational support should be provided to promote protective sexual behaviour among HIV-positive women. Also, Patrao et al. showed that only $38.2 \%$ of high-risk women used condoms as a prevention method and that higher HIV prevention knowledge leads to higher condom-use negotiation skills [25]. The level of awareness was correlated with the duration of membership of a positive club, which can be attributed to weekly training classes at the club; therefore, those who have been among the club's membership for a longer period have benefited from educational materials more frequently.

Average income and financial resources of individuals in this study belonged to the low economic decile groups. It is quite clear that poverty causes men and women to become vulnerable to HIV, especially for those active in the sex industry. Poverty imposes restrictions on the use of condoms and increases the likelihood of an infection. Because women face more financial limitations than men and are therefore more vulnerable in this regard, the likelihood of unprotected sex is higher in these individuals. There are two main reasons for this problem: firstly, the economic and livelihood needs prevent women from having safe sex; and secondly, they may neglect to use condemns due to pressure and fear of violence [26].

A total of $4.80 \%$ of people never used alcohol before sex. Investigating this variable is valuable because alcohol consumption has been consistently associated with high-risk sexual behaviours, and if used (especially alcohol poisoning), there would be elevated risk of a negotiation failure to use condoms and may even lead to conflict between couples [22]. Also, 95.8\% of the participants never used drugs before sex. However, $17.3 \%$ of the sexual partners were injecting drug users and $27 \%$ were non-injecting drug users. Drug use can have a negative impact on sexual intercourse because many addicts use drugs as an incentive to succeed in sexual matters or to obtain unreasonable or exceptional sexual pleasures. High-risk sexual behaviours are more common in people who abuse substances, regardless of their gender, and there is a greater interest in having different sexual partners as well as frequent sexual intercourse without the use of preventive measures in these individuals, which in turn increases the risk of transmission of sexually transmitted diseases [22, 23].

Many women attributed the non-use of condoms in anal and oral sex to the painful experience and impossibility of using condoms, respectively. As was seen in the present study, participants had moderate or little awareness of HIV transmission through anal and oral sex, respectively. The majority of participants of the above study also had awareness of the vaginal transmission routes of HIV, but were unaware of HIV transmission through anal and oral sex [21].

\section{Conclusions}

The results of the present study indicate poor protective sexual behaviours in HIV-positive women. Considering that the most common route of HIV transmission in recent years is high-risk sexual behaviours, it is important to consider measures to replace risky behaviours with healthy sexual behaviours for the general public. Behavioural interventions to promote the use of condoms or to reduce risky sexual behaviours include individual counselling, skill training, coping strategies and discourse, peer education, and social and educational support. It is possible to prevent rapid HIV transmission through high-risk sexual behaviour by using these measures and raising public awareness. It is suggested that a study with a higher sample size be carried out to compare sexual protection behaviour in men and women.

\section{Acknowledgments}

This article is the result of a master's thesis on midwifery consultation, and is sponsored by the Alborz University of Medical Sciences. Hereby, the authors express their gratitude to Alborz University of Medical Sciences, the personnel working in the AIDS Research Centre of Iran and the HIV-positive patients who helped us in this project.

\section{Conflict of interest}

The authors declare no conflict of interest with respect to the research, authorship, and/or publication of this article.

\section{References}

1. Mirzazadeh A, Shokoohi M, Navadeh S, et al. Underreporting in HIV-related high-risk behaviors: comparing the results of multiple data collection methods in a behavioral survey of prisoners in Iran. Prison J 2018; 98: 213-228.

2. World Health Organization. HIV/AIDS Data and statistics: 2019 HIV Country profiles. Available from: https://www.who.int/hiv/ data/en/

3. UNAIDS. UNAIDS Data; 2018 [updated 2018; cited 8 March 2019]. Available from: www.unaids.org/sites/default/files/media_asset/ unaids-data-2018_en.pdf

4. Ministry of Health and Medical Education. Statistics of the Department of AIDS Prevention and Control of Diseases (2018). Unpublished.

5. Ministry of Health and Medical Education. World AIDS Day Report. Islamic Republic of Iran; 2017. Available from: http://behdasht.gov.ir/?siteid=1\&pageid=1508\&newsview $=169553$

6. Sadeghi Zerisfi A, Zeinaddiny Maymand Z, Haghdoost AA. The effect of received services on mental heath status, life expectancy and social support of HIV-infected women referring to the Kerman Service Center. Iranian J Epidemiol 2018; 14: 45-52. 
7. Robinson JL, Narasimhan M, Amin A, et al. Interventions to address unequal gender and power relations and improve self-efficacy and empowerment for sexual and reproductive health decision-making for women living with HIV: a systematic review. PLoS One 2017; 12: e0180699.

8. Fleming PJ, Dworkin SL. The importance of masculinity and gender norms for understanding institutional responses to HIV testing and treatment strategies. AIDS 2016; 30: 157-158.

9. Lotfi R, Ramezani Tehrani F, Yaghmaei F, et al. Barriers to condom use among women at risk of HIV/AIDS: a qualitative study from Iran. BMC Women's Health 2012; 12: 13.

10. Lotfi R, Ramezani Tehrani F, Merghati Khoei E, et al. How do women at risk of HIV/AIDS in Iran perceive gender norms and gendered power relations in the context of safe sex negotiations? Arch Sex Behav 2013; 42: 873-881.

11. Wagman JA, Samet JH, Cheng DM, et al. Female gender and HIV transmission risk behaviors among people living with hiv who have ever used injection drugs in St. Petersburg, Russia. AIDS Behav 2018; 22: 2830-2839.

12. Woods TM, Altman CE, Chavez S, et al. Gender, migration and perceptions of HIV risk in Mexico. Cult Health Sex 2018; 20: 1333-1346.

13. Pharr JR, Enejoh V, Mavegam BO, et al. A cross-sectional study of the role of HIV/AIDS knowledge in risky sexual behaviors of adolescents in Nigeria. Int J High Risk Behav Addict 2017; 6: e63203.

14. Sadler S, Tosh J, Pennington R, et al. A cost-effectiveness analysis of condom distribution programmes for the prevention of sexually transmitted infections in England. J Epidemiol Community Health 2017; 71: 897-904.

15. Widman L, Choukas-Bradley S, Noar SM, et al. Parent-adolescent sexual communication and adolescent safer sex behavior: a metaanalysis. JAMA Pediatr 2016; 170: 52-61.

16. Lotfi R, Ramezani Tehrani F, Yaghmaei F, Hajizadeh E. Developing a valid and reliable instrument to predict the protective sexual behaviors in women at risk of human immunodeficiency virus. Iran Red Crescent Med J 2014;16: e14682.

17. Pinkerton SD, Abramson PR. Effectiveness of condoms in preventing HIV transmission. Soc Sci Med 1997; 44: 1303-1312.

18. Moazen B, Hajizadeh S, Nedjat S, et al. Determinants of consistent condom use among Iranians living with HIV/AIDS: implication for prevention. Int J High Risk Behav Addict 2018; 6: e63237.

19. Deuba K, Kohlbrenner V, Koirala S, et al. Condom use behaviour among people living with HIV: a seven-country community-based participatory research in the Asia-Pacific region. Sex Transm Infect 2018; 94: 200-205.

20. Hajizadeh SH, Nedjat S, Setayesh HR, et al. Associated factors with condom use amongst people living with HIV referred to triangular clinics of Universities of Medical Sciences in Tehran. Hakim Health Systems Research Journal 2012; 16: 144-152.

21. Malery khah Langeroudi Z, Rahimi movaghar A, Delbarpour Ahmadi S, et al. Barriers of condom use among female sex workers in Tehran, a qualitative study. J Sch Public Health Inst Public Health Res 2014; 12: 23-34.

22. Davis KC, Gulati NK, Neilson EC, et al. Men's coercive condom use resistance: the roles of sexual aggression history, alcohol intoxication, and partner condom negotiation. Violence Against Women 2018; 24: 1349-1368.

23. Dworkin SL, Fleming PJ, Colvin CJ. The promises and limitations of gender-transformative health programming with men: critical reflections from the field. Cult Health Sex 2015; 17 Suppl 2: S128-143.

24. Bayat Jozani Z, Seyedalinaghi S, Moayedi-Nia S, et al. Efficacy of a condom negotiation intervention among high risk Iranian women in Tehran, Iran. J Int Transl Med 2018; 6: 105-112.

25. Patrao AL, McIntyre TM. Socio-demographic, marital, and psychosocial factors associated with condom use negotiation selfefficacy among Mozambican women at risk for HIV infection. Int J Behav Med 2017; 24: 846-855.
26. Reeves A, Steele S, Stuckler D, et al. Gender violence, poverty and HIV infection risk among persons engaged in the sex industry: cross-national analysis of the political economy of sex markets in 30 European and Central Asian countries. HIV Med 2017; 18: 748-755. 